\title{
ENTREVISTA
}

\section{Entrevista de Pauline Kleingeld aos Cadernos}

\author{
Bruno Nadai \\ Professor de filosofia na UFABC \\ Cauê Polla \\ Doutor em filosofia pela USP \\ Monique Hulshof \\ Professora de filosofia na UFABC
}

Em visita à Universidade de São Paulo, Pauline Kleingeld concedeu esta entrevista aos Cadernos de Filosofia Alemã : Crítica e Modernidade, após um intenso debate realizado no Colóquio Internacional: Política, Direito e Cosmopolitismo, em agosto de 2012, em que foram discutidos seu novo livro Kant and Cosmopolitism: The Pbilosopbical Ideal of World Citizenship e alguns de seus artigos sobre gênero e justiça. Professora da Universidade de Groningen, na Holanda, e pesquisadora da filosofia moral e política de Kant, particularmente conhecida por seus diversos livros e artigos sobre a compreensão kantiana sobre a história, Kleingeld recupera ao longo da entrevista alguns elementos de sua trajetória intelectual, esclarece aspectos de sua interpretação da filosofia prática de Kant e retoma algumas questões surgidas ao longo do Colóquio, especialmente aquelas sobre a atualidade do cosmopolitismo kantiano e sobre interpretações feministas do problema da justiça.

Monique: Você é bolandesa, seu doutorado foi publicado em alemão, e seu livro recente sobre cosmopolitismo foi publicado em inglês. Você poderia nos dizer um pouco sobre como se deu sua formação em diferentes linguas e em diferentes países?

Kleingeld: Claro. Eu estudei em Leiden, na Holanda, e depois do meu mestrado eu fui para Frankfurt e estudei na Alemanha por um ano e meio, depois comecei a trabalhar na minha tese. Nessa época, o alemão 
era minha segunda língua, eu era mais fluente em alemão do que em inglês. Não tinha sentido escrever minha tese em holandês por dois motivos: primeiramente, ninguém a leria, exceto os membros da banca, pois a comunidade filosófica de língua holandesa é muito pequena, em segundo lugar, eu estudei em Frankfurt com Habermas e queria que ele pudesse ler a tese, então eu tinha que escrever em outro idioma e não me sentia confortável, na época, para escrever em inglês, por isso a escrevi em alemão. Eu não sabia que acabaria trabalhando nos Estados Unidos. Se eu soubesse disso, certamente teria escrito a tese em inglês.

\section{Monique: E quais foram as influências em sua formação nesta época?}

Kleingeld: Meu orientador não era um especialista em Kant. Eu queria apenas estudar Kant e ele me deixou fazer isso. Basicamente, passei a maior parte do tempo com os textos e a bibliografia secundária. Eu havia começado no Departamento de Estudos da Religião em Leiden, e só passei à filosofia gradualmente. Recebi uma bolsa de monitoria que incluía ensinar um curso introdutório de história da filosofia, embora eu só tivesse tido aquele curso e um outro em filosofia. Passei o ano todo tentando ficar uma semana à frente dos meus alunos e foi assim que eu estudei filosofia. Depois disso eu decidi escrever minha dissertação de mestrado em filosofia. Mas, quando terminei meu mestrado, eu ainda sentia que não tinha estudado filosofia de maneira adequada. Fui para Frankfurt, pois já sabia que queria escrever minha tese sobre Kant, e queria evitar ficar presa no conjunto de questões filosóficas do século XVIII. Eu queria passar dois semestres em um excelente departamento de filosofia e, porque Habermas foi influenciado por Kant, mas também pela filosofia dos duzentos anos depois de Kant, pensei que estudar com ele me permitiria dar um passo atrás e manter uma distância filosófica em relação a Kant, e tudo acabou dando certo. Foi um período fantástico. Assim, de certo modo, pode-se dizer que Habermas, e muitos outros em Frankfurt, foram uma influência, embora eu não acredite que tenha havido alguma influência direta na minha interpretação de Kant. O que foi importante para minha interpretação da filosofia kantiana foi que, como parte do currículo dos estudos de religião, eu tinha que fazer muita exegese bíblica (pesquisar o sentido exato de termos-chaves da época em que os textos foram escritos, comparar comentários, e assim por diante), acho que esse foi um modo muito bom de aprender como ler os textos. $\mathrm{O}$ pano de fundo religioso sempre ofereceu algumas vantagens para 
mim, não apenas por conta da habilidade para a leitura, que acredito ter ganhado, mas também porque muitos pensadores do século XVIII ainda estavam trabalhando dentro de um quadro teológico e com vocabulário teológico. Ter certa familiaridade com a teologia se mostrou bastante útil.

Bruno: Gostaria de insistir nesta questão da sua formação. Você acabou de dizer que estudou com Habermas porque ele é, de certo modo, kantiano, mas seus interesses filosóficos não estão restritos à filosofia kantiana sob um ponto de vista bistórico. Mas sua tese de doutorado é exatamente sobre a filosofia da bistória de Kant sob uma perspectiva sistemática. Já o seu livro sobre o cosmopolitismo kantiano trata sistematicamente de problemas kantianos, mas também contextualiza os debates de Kant e aborda os debates contemporâneos em filosofia política com respeito à questão do cosmopolitismo. Gostaria de perguntar como você vê a possibilidade de apropriação de um filósofo político clássico como Kant para pensar problemas contemporâneos.

Kleingeld: Bem, eu acredito que o caso de Kant é muito frutífero. Talvez possa não ser frutífero em todos os casos, mas o que eu descobri estudando Kant foi que frequentemente há muitos recursos nos textos antigos que podem ser usados nos debates contemporâneos. Eu descobri ser muito útil trabalhar com discussões contemporâneas e históricas. Tendo em mente as questões que são levantadas nos debates atuais, pode-se aproveitar mais os textos antigos porque se compreende melhor as questões filosóficas. Se não se compreende uma dada questão filosófica não é possível encontrar a resposta no texto antigo. E, por outro lado, os textos antigos contém recursos filosóficos que nem sempre são utilizados completamente nos debates atuais. Assim, no caso do patriotismo, por exemplo, eu pensava inicialmente que para o livro sobre cosmopolitismo, eu poderia escrever apenas um parágrafo sobre o patriotismo. Mas eu acabei escrevendo dois artigos inteiros sobre o tema, um sobre o patriotismo cosmopolita de Kant e outro sobre o patriotismo kantiano. Ao examinar a compreensão de Kant acerca do patriotismo, eu encontrei uma resposta a uma certa objeção que é geralmente levantada contra as abordagens do cosmopolitismo de Kant e dos kantianos, a saber, a objeção de que essas abordagens não dão conta de obrigações especiais. Acho que compreendi melhor a visão de Kant sobre o patriotismo porque eu estava consciente daqueles desafios filosóficos. O debate atual me ajudou a colocar questões a partir das quais os textos antigos se mostraram muito mais interessantes do que eu havia primeiramente pensado. Para voltar à sua questão: é claro que nem sempre sabemos quando figuras 
históricas têm algo a acrescentar aos debates atuais. No caso de Kant - em especial no caso do cosmopolitismo no último quarto do século XVIII na Alemanha - acho que funcionou muito bem.

Cauê: Gostaria de colocar uma dupla questão, retornando às perguntas do Bruno e da Monique. Estive duas vezes na Holanda e vivenciei um pouco da atmosfera filosófica de lá e gostaria de saber de você-que teve toda essa experiência desde a sua graduação - como são os estudos filosóficos na Holanda e como eles se modificaram até boje. Além disso, qual seria o espaço para Kant nos estudos de filosofia na Holanda?

Kleingeld: Esta é uma questão complicada. Como não tenho conhecimento de todos os trabalhos em todo lugar é difícil dar uma resposta que faça justiça ao trabalho que tem sido feito na Holanda como um todo. Mas, desde que eu me inseri na filosofia, tem havido muito interesse em Kant na Holanda. O cenário filosófico como tal não é muito amplo, mas sempre tive colegas com quem conversar sobre a pesquisa em Kant. Este é um aspecto muito bom de viver em um país pequeno: é possível encontrar facilmente os colegas de outras universidades. Nos EUA, as distâncias são maiores, então costuma ser mais difícil fazer encontros do que na Holanda. Eu também acho o nível acadêmico muito alto. Sempre gostei muito de trabalhar lá.

Bruno: Na comunidade filosófica bolandesa é regra publicar em outras línguas além do bolandês, como vocêfez em seu livro sobre filosofia da bistória, Fortschritt und Vernunft1, publicado em alemão e em seu livro recente, Kant and Cosmopolitanism², publicado em inglês. É comum publicar em outras linguas?

Kleingeld: É comum que as pessoas publiquem em inglês. No meu próprio departamento, há uma expectativa explícita de que se publique nos melhores periódicos em suas áreas e, para a grande maioria das áreas, estes periódicos são em língua inglesa. Além disso, você alcança um público mais amplo em inglês. Então, se você realiza uma pesquisa e elabora uma nova tese sobre algo, faz sentido dividir isso com a mais ampla comunidade filosófica trabalhando neste assunto e, na maioria dos casos, é a comunidade anglófona.

1. KLEINGELD, P. Fortschrift und Vernunft: Zur Gescbichtspbilosopbie Kants. Würzburg: Königshausen \& Neumann, 1995.

2. KLEINGELD, P. Kant and Cosmopolitanism. The Pbilosopbical Ideal of World Citizenship. New York: Cambridge University Press, 2012. 
Cauê: E existem traduções sobre Kant? Há algum interesse nisso?

Kleingeld: Sim, há muito interesse público em filosofia, existindo, por exemplo, uma revista filosófica que se dirige ao público leigo, um público geral interessado em filosofia. É a maior revista filosófica no mundo, exatamente por existir um forte interesse em filosofia. A maioria dos textos principais de Kant tem sido traduzida. Mas, quando se trata de publicar o resultado de pesquisa acadêmica filosófica, a tendência é publicar em Inglês. Isso não quer dizer que você não possa publicar em holandês e traduzir ou divulgar em holandês. Mas, cada vez mais, a linguagem para resultados originais das pesquisas é em inglês.

Bruno: Gostaria de colocar agora uma questão mais teórica. Em seu livro Fortschritt und Vernunft, sobre a filosofia da bistória de Kant, você argumentou que, desde a contribuição de Darwin à biologia evolutiva, a teleologia natural de Kant não pode mais se sustentar. Uma vez que há uma forte conexão entre a filosofia da bistória de Kant e sua teleologia natural, a mudança de uma descrição finalística da biologia para uma darwinista acarreta implicações significativas quanto à possibilidade de uma abordagem kantiana contemporânea da filosofia da bistória. Assim, gostaríamos de perguntar, o que está vivo e o que está morto na filosofia da bistória de Kant?

Kleingeld: Pensei muito sobre isto e acredito que talvez se possa utilizar o modelo teleológico de maneira frutífera. Eu digo "talvez" porque é papel de um historiador descobrir o quão útil é este modelo, são necessários critérios claros sobre como avaliar a utilidade de tal modelo para descrever o curso da história. Ainda que a base não tenha ligação com modelos usados em biologia, por exemplo, isto não significa que este modelo não possa ser usado como um modelo para a historiografia. Escrevi um artigo exatamente sobre este tópico ${ }^{3}$, argumentando que o que Kant fez em Ideia de uma bistória universal de um ponto de vista cosmopolita foi forjar uma ideia reguladora para ordenar o caos dos fatos históricos segundo um padrão mais ou menos regular. Isto ainda pode ser feito e há historiadores que acreditam que é frutífero fazê-lo. Eles argumentam que, ainda que historiadores se foquem em períodos históricos ou eventos muito menores do que "a história universal", por trás há sempre uma pressuposição do todo. Se isto é verdade, então se poderia ver se o

3. KLEINGELD, P. Kant on Historiography and the Use of Regulative Ideas. In: Studies in History and Philosophy Part A, vol. 39 N.4, December 2008, pp. 523-528. 
modelo teleológico pode ser frutífero. Ora, não estou dizendo que ele deveria ser utilizado. Estou apenas dizendo que isso deve ser decidido por aqueles que se especializam nessa área.

Monique: Eu tenbo outra questão teórica, agora sobre seus artigos sobre teoria do feminismo. Você disse ontem que vocêe Joel Anderson assumiam uma posição neutra no debate liberal-igualitário ao não definirem o conceito de justiça e manterem o conceito de familia amplo o suficiente para contribuir ao debate. Mas você não especificou que debate é esse. Quem são as pessoas com quem você e Anderson estão debatendo diretamente?

Kleingeld: Todos os autores que mencionamos utilizando a taxonomia das quatro perspectivas sobre a relação entre justiça, amor e família. De fato, procuramos dialogar tanto com as pessoas que acreditam que uma das preocupações com a justiça seria uma ameaça ao amor, como também com as pessoas que acreditam que uma preocupação com o amor seria uma ameaça à justiça, e pessoas que enxergam uma tensão entre amor e justiça ou que consideram um subsumido ao outro. É, portanto, um grupo bem amplo ${ }^{4}$.

Bruno: Gostaria de fazer outra questão relacionada ao livro Kant and Cosmopolitanism. Nesse livro recém publicado, você sustenta que bá uma clara e relevante mudança na teoria política de Kant dos anos 80 para os 90, especialmente em sua teoria do direito público. Desde Teoria e Prática Kant se compromete com um ideal de republicanismo. De acordo com sua leitura, esse comprometimento com o republicanismo levou Kant a diversas outras mudanças, como aquelas em sua teoria do direito internacional, seus pensamentos sobre raça e colonialismo e também na própria ideia de Direito Cosmopolita. Vocêpoderia falar um pouco sobre esta mudança na teoria de Kant do direito público e por que seu ideal republicano é uma espécie de chave para explicar todas essas mudanças?

Kleingeld: Bem, tive esta ideia na parte final do processo de escrita do livro. Redigi os capítulos individuais e então me dei conta de que em muitos capítulos eu argumentava que havia uma mudança na perspectiva de Kant, então essa virou uma das teses principais do livro. Não era algo de que eu estivesse consciente quando comecei a escrever. Pode-se encontrar evidências da mudança da compreensão de Kant quanto à federação internacional que ele propõe. Nas décadas de 1770

4. O artigo referido, de autoria de Pauline Kleingeld e Joel Anderson, "Justiça como valor familiar", será publicado em Hypatia. 
e 1780, em Ideia de uma bistória universal, por exemplo, ele propõe de forma explícita e clara que uma federação internacional deve ter poderes coercitivos. Não há uma defesa de uma federação frouxa <loose league >. Por outro lado, em meados da década de 1790, em Para a Paz Perpétua, ele defende a ideia de uma federação frouxa <loose league>. Então, se coloca a questão: como isto se relaciona com a ideia de uma federação com poderes coercitivos? Eu explico esta mudança nos termos do ideal republicano de Kant, na medida em que esse ideal envolve a autonomia política coletiva do povo enquanto um república. Este ideal não estava lá antes, então este é um ponto no qual se pode ver uma importante mudança na posição de Kant. Além disso, a noção de direito cosmopolita é completamente nova em meados da década de 1790. O direito cosmopolita foi introduzido depois que Kant desistiu de endossar o colonialismo. Desse modo, no contexto da descrição das raças feita por Kant, pode-se observar que ele defendeu, inicialmente, uma hierarquia racial e que, depois, ele não mais o fez. Esses são alguns exemplos da mudança das ideias de Kant e, é claro, também em relação ao desenvolvimento de sua teoria política como tal, na qual podemos vê-lo desenvolver sua noção de república e cidadania em sentido pleno.

Bruno: Contrastando com abordagens formalistas da moral em relação à filosofia prática de Kant, você dá mais ênfase ao que chamarei de "problemas de aplicação" da filosofia prática de Kant, tais como aqueles presentes na filosofia da bistória de Kant, na pedagogia, na política e assim por diante. Você concorda com essa caracterização do seu trabalbo? De um ponto de vista sistemático, como você compreende a relação entre os momentos de fundamentação da filosofia prática de Kant e o de sua aplicação ou seus momentos de realização? Seriam eles dois momentos separados - um puro e outro impuro, como designou Robert Louden - ou é como se Kant estivesse o tempo todo mais preocupado com a questão da efetivação, de modo que o momento de fundamentação é também desenvolvido em vista do comprometimento especificamente bistórico de Kant, como sustenta Allan Wood? Como você descreveria estes dois momentos?

Kleingeld: É interessante que você descreva o livro assim, porque eu mesma senti que sempre me mantive longe das questões de "aplicação". Toda minha discussão foi acerca de princípios. Eu argumento, por exemplo, que o cosmopolitismo kantiano é, em geral, compatível com o patriotismo kantiano, mas eu não examino o que nós deveríamos fazer concretamente. O mesmo vale para os outros capítulos. Não tiro conclusões sobre os deveres específicos em face da fome mundial, por exemplo. Eu não faço isso simplesmente porque não é meu projeto, que 
é um projeto na história da filosofia. Também não considero o livro como "aplicado" porque, em relação a este projeto, eu sempre senti que ainda faltava a fundamentação. A fundamentação de uma descrição do status moral ou dos direitos políticos não está presente. É claro que isto é também apenas uma questão de definir minha área específica de pesquisa. Não se pode fazer tudo. Mas não há fundamentação da ética kantiana ou uma fundamentação do princípio do direito neste livro. Então, também sob este aspecto, o livro não fornece uma "aplicação". Estou trabalhando agora justamente nessas questões de fundamentação da teoria moral, porque eu senti que este seria, logicamente, o próximo passo. Depois disso, talvez eu volte ao cosmopolitismo e esteja de fato habilitada para aplicar os resultados do meu trabalho atual.

Monique: Para finalizar, uma última questão sobre a posição das mulberes no mundo acadêmico na Europa e também no Brasil: quando estive na Alemanba, bavia um grande debate sobre a presença de mulheres na área acadêmica da filosofia, pois em outras áreas podemos dizer que bá um equilíbrio de 50\%-50\% entre professores bomens e mulberes. Mas na filosofia ainda existe um grande problema, pois, de acordo com que pesquisei, em todos os departamentos de filosofia não bá mais do que 20 ou $30 \%$ de professoras. No seu departamento, eu vi que bá seis professores e apenas duas professoras...

Kleingeld: Sim...e isto é um grande progresso! Por cinco anos, eu fui a única professora titular de filosofia no país. Há treze universidades na Holanda, quase todas tem um departamento de filosofia e todos estes departamentos têm professores titulares. Eu não fui a primeira, mas naquela altura eu era a única porque a anterior havia se aposentado. Nos EUA a situação é muito diferente, há uma tradição mais antiga quanto à participação das mulheres na academia. Mas, mesmo ali, o percentual de professoras plenas não é mais do que 20 ou $30 \%$. $\mathrm{Na}$ Holanda há um aumento de doutorandas mulheres, mas elas continuam abandonando suas carreiras acadêmicas. Tenho esperança de que isto mude e melhore. A Holanda costumava ter um dos menores percentuais de participação feminina na força de trabalho remunerada no mundo, isso mudou rapidamente nos últimos vinte anos. Havia um modelo do homem como provedor da família, em parte porque o país é muito rico então não havia uma pressão para as esposas trabalharem. Mas tem havido uma tendência crescente em direção a uma maior participação das mulheres na força de trabalho. Agora há, pelo menos, quatro professoras titulares na filosofia, e isto é - comparado com apenas alguns anos antes - um aumento enorme. 